\title{
Effect of utilizing developed gestational diabetes mellitus guideline on pregnancy and childbirth outcomes
}

\author{
Enas Sabry Fathy Elbeltagy ${ }^{1}$, Nahed Fikry Hassan khedr ${ }^{* 2}$, Nadia Youssef Ahmed Abd-Ella ${ }^{2}$ \\ ${ }^{1}$ Faculty of Nursing, Mansoura University, Egypt \\ ${ }^{2}$ Woman's Health and Midwifery Nursing Faculty of Nursing, Egypt
}

Received: October 6, 2020

Accepted: November 26, 2020

Online Published: December 16, 2020

DOI: $10.5430 / \mathrm{cns} . v 9 \mathrm{n} 1 \mathrm{p} 15$

URL: https://doi.org/10.5430/cns.v9n1p15

\begin{abstract}
Background: Gestational Diabetes Mellitus (GDM) is one of the most common medical health problems that may happen during pregnancy and may lead to a range of short and long-term maternal, fetal as well as neonatal complications. However, effective management and education on GDM self-care measures improve pregnancy outcomes for both women and their neonates.

Aim: The study was carried out to evaluate the effect of utilizing developed gestational diabetes mellitus guideline on pregnancy and childbirth outcomes.

Methods: A quasi-experimental research design was used at Antenatal Clinic of Obstetric and Gynecological Specialty Center at Mansoura University Hospitals, Mansoura city. A purposive sample of 126 pregnant women diagnosed with GDM, assigned to the intervention group $(n=63)$ who utilized the Gestational Diabetes Mellitus Guideline (GDMG) of care in addition to routine antenatal care and control group $(n=63)$ who followed routine antenatal care only. Tools: Three tools were used to collect data from participants as A structured interview schedule, maternal assessment record and fetal \& neonatal assessment record.

Results: The current study findings indicated that, there was a highly statistical significant reduction of body mass index and the mean random blood glucose levels at $34 \& 37$ weeks' of pregnancy after intervention in the GDMG group than control groups ( $p$ $<.001$ ). Also, there was a statistical significant reduction in the occurrence of maternal complications as gestational hypertension, preeclampsia, preterm labor and polyhydramnios in the GDMG group. Similarly, the neonates of the GDMG group had better Apgar scores after birth \& lower incidence for developing neonatal complications as prematurity, respiratory distress syndrome and NICU admission.

Conclusions and Recommendations: This study showed that, pregnant women with GDM who utilized the GDMG had better maternal \& neonatal outcomes than those who did not utilize it. It is recommended to provide a manual GDMG to all pregnant women with GDM for better lifestyle changes \& maintaining self-management regimen as well as better pregnancy outcomes.
\end{abstract}

Key Words: Gestational diabetes mellitus, Guideline, Pregnancy outcomes, Childbirth outcomes

\section{INTRODUCTION}

Pregnancy and childbirth are considered as a normal physiological phenomenon that occurs in all women. Approxi- mately, about $10 \%$ of pregnant women are at risk to develop maternal and fetal health problems during pregnancy such as pregnancy induced hypertension (PIH), eclampsia, hyper-

\footnotetext{
* Correspondence: Nahed Fikry Hassan khedr; Email: dr.nahid2020@hotmail.com; Address: Woman’s Health and Midwifery Nursing Faculty of Nursing, Egypt.
} 
emesis gravidarum and gestational diabetes mellitus. Thus, requires serious life modification as well as special care during pregnancy and childbirth. ${ }^{[1]}$

Gestational Diabetes Mellitus (GDM) is a diabetes type which defined as any degree of glucose intolerance or abnormal glucose metabolism with the onset or first recognition during pregnancy and usually resolves after birth. This definition can include women with previously undiagnosed diabetes as well as those who become transiently hyperglycemic because of pregnancy-induced insulin resistance. ${ }^{[2]}$

The prevalence of GDM increases rapidly especially among women over the age of 35 years. There were an estimated 204 million women worldwide had GDM. This number is predictable to increase to 308 million by 2045 . Furthermore, there were about 21.3 million or $16.2 \%$ of live births suffering from hyperglycemia during pregnancy due to gestational diabetes, about one to seven of them are affected by GDM $^{[3,4]}$

The exact causes of GDM are still unclear but there are several risk factors that lead to the GDM among pregnant women as maternal age over 30 years, high parity, family history of diabetes in a first degree relatives, previous GDM, obesity, prior macrosomic baby $(<4.5 \mathrm{~kg})$, malformed \& unexplained fetal/perinatal loss, recurrent vaginal candidiasis and repeated miscarriage. ${ }^{[5]}$

GDM does not cause any noticeable signs or symptoms, but some women with GDM rarely demonstrate increased thirst, increased urination, fatigue, nausea and vomiting, bladder infection, yeast infections and blurred vision. ${ }^{[6]}$ It is associated with both short and long term adverse outcomes for mothers and their offspring as pregnant women with GDM are more predisposed to developing pregnancy-induced hypertension syndrome, polyhydramnious, premature rupture of membranes, infection and macrosomia. Moreover, the incidences of neonatal asphyxia, respiratory distress syndrome, hypoglycemia, hyperbilirubinemia and other neonatal complications are higher in GDM women during perinatal period which can lead to neonatal developmental disorders and even neonatal death. ${ }^{[7]}$

Recent studies have found that the early management and utilization of nursing guideline of GDM help in improving the prognosis of pregnant women and their fetuses. So, GDM counseling during pregnancy improves the women's ability to cope with their disease and make informed decisions regarding management of GDM with dietary changes, exercise and self-monitoring of blood glucose level. Also, It motivate the women to change any harmful dietary and lifestyle habits which is important for better pregnancy outcomes. ${ }^{[8-10]}$
The role of the maternity nurse in caring of women with GDM is considered an essential part on prevention and reduction of GDM complications that may have direct impact on women health during antepartum, intrapartum \& postpartum periods as well as their infants. This can be achieved by providing pregnant women with appropriate information aimed to increase, correct their knowledge and empowering women with GDM to have a positive attitude toward GDM including diet regimen, exercise, self monitoring blood glucose level and GDM medical treatment throughout their pregnancy period. Furthermore, nurses should provide advice and support to reduce the risks and complications of GDM for better pregnancy outcomes. ${ }^{[11,12]}$

\subsection{Significance of the study}

GDM is a major health problem in developing countries. The overall prevalence of GDM in Middle East and North Africa had the highest prevalence (12.9\%) compared to Europe which had the lowest prevalence (5.8\%). It was the fifth leading cause of maternal death. ${ }^{[13,14]}$ Regarding to the prevalence of GDM among pregnant women in Egypt is $2 \%-14 \%$ of all pregnancies, this may be related to the lack of education and sociocultural factors in Egypt, thus lead to improper and substandard antenatal care, failure of screening high risk pregnancies and delaying of referral to the appropriate health facilities at appropriate time. ${ }^{[15]}$

Moreover, Gestational diabetes mellitus have serious adverse effect on mother's and newborn health which lead to increasing the rates of maternal and prenatal morbidity and mortality. ${ }^{[16]}$ Although, there are several guidelines concerned with providing care for gestational diabetic women, there were 1.5 million deaths worldwide caused directly by Gestational diabetes mellitus. ${ }^{[13]}$ So, the researcher will adapt all these guidelines to develop a comprehensive nursing guideline to improve care for gestational diabetic women and improve maternal and neonatal outcomes.

\subsection{Aim of the study}

The study aimed to evaluate the effect of utilizing developed gestational diabetes mellitus guideline on pregnancy and childbirth outcomes.

\subsection{Study hypothesis}

One hypothesis was tested to achieve the present study aim "Pregnant women with gestational diabetes mellitus who utilize gestational diabetes mellitus guideline have better pregnancy and childbirth outcomes than those who don't utilize it". 


\section{SubJeCtS AND Methods}

\subsection{Design}

A quasi-experimental study design was used.

\subsection{Setting}

The current study was conducted in the Antenatal Clinic of Obstetric and Gynecological Specialty Center at Mansoura University Hospitals, Mansoura city, Dakahlia governorate, Egypt. The setting consists of one flour divided into six parts; reception part, sonar part, antenatal examination section, gynecological examination section, vesicular mole section and room for nursing staff. The official working hours at the antenatal clinic begins at 9 am and ends at 12 pm daily except Thursday, the routine antenatal care was provided by two nurses and 5 obstetricians (consultant, specialist assistant, specialist and two juniors). The flow rate of gestational diabetic women was 7-8 women per week.

\subsection{Sampling}

A purposive sample of 126 pregnant women diagnosed with GDM who were admitted to the previously described study setting between May 2019 to December 2019, enrolled in this study when fulfilled the following inclusion criteria: gestational age between 28-32 weeks, having single living fetus, regular follows up schedule of antenatal visits, can read and write and agreed to participate in the study. Exclusion criteria include the following: pregnant women suffering from other medical diseases as hypertension, diabetes mellitus or suffering from any obstetrical problems as pregnancy induced hypertension, preterm labor. Pregnant women who fulfilled the inclusion criteria were assigned to intervention group (who utilized the GDMG of care in addition to routine antenatal care) \& control group (who followed routine antenatal care only).

\subsection{Sample size calculation}

Based on the data from literature (Azzam \& El Sharkawy, 2015). Considering level of significance of 5\%, and power of study of $80 \%$, the sample size can be calculated using the following formula (see Equation 1):

$$
n=\left[\frac{2\left(Z_{\frac{\alpha}{2}}+Z_{\beta}\right)^{2} \times p(1-p)}{\left(p_{1}-p_{2}\right)^{2}}\right]
$$

Where $n=$ sample size required in each group, $p=$ pooled proportion (proportion of event in group $1+$ proportion of event in group 2)/2, $p_{1}-p_{2}=$ difference in proportion of events in both groups, $Z_{\alpha_{2}}$ : This depends on level of significance, for $5 \%$ this is $1.96, Z_{\beta}$ : This depends on power, for $80 \%$ this is 0.84 ,

$n=\left[2(1.96+0.84)^{2} \times 0.45(1-0.55)\right] /(0.25)^{2}=62.4$.

So, the required sample size per group was 63 pregnant women.

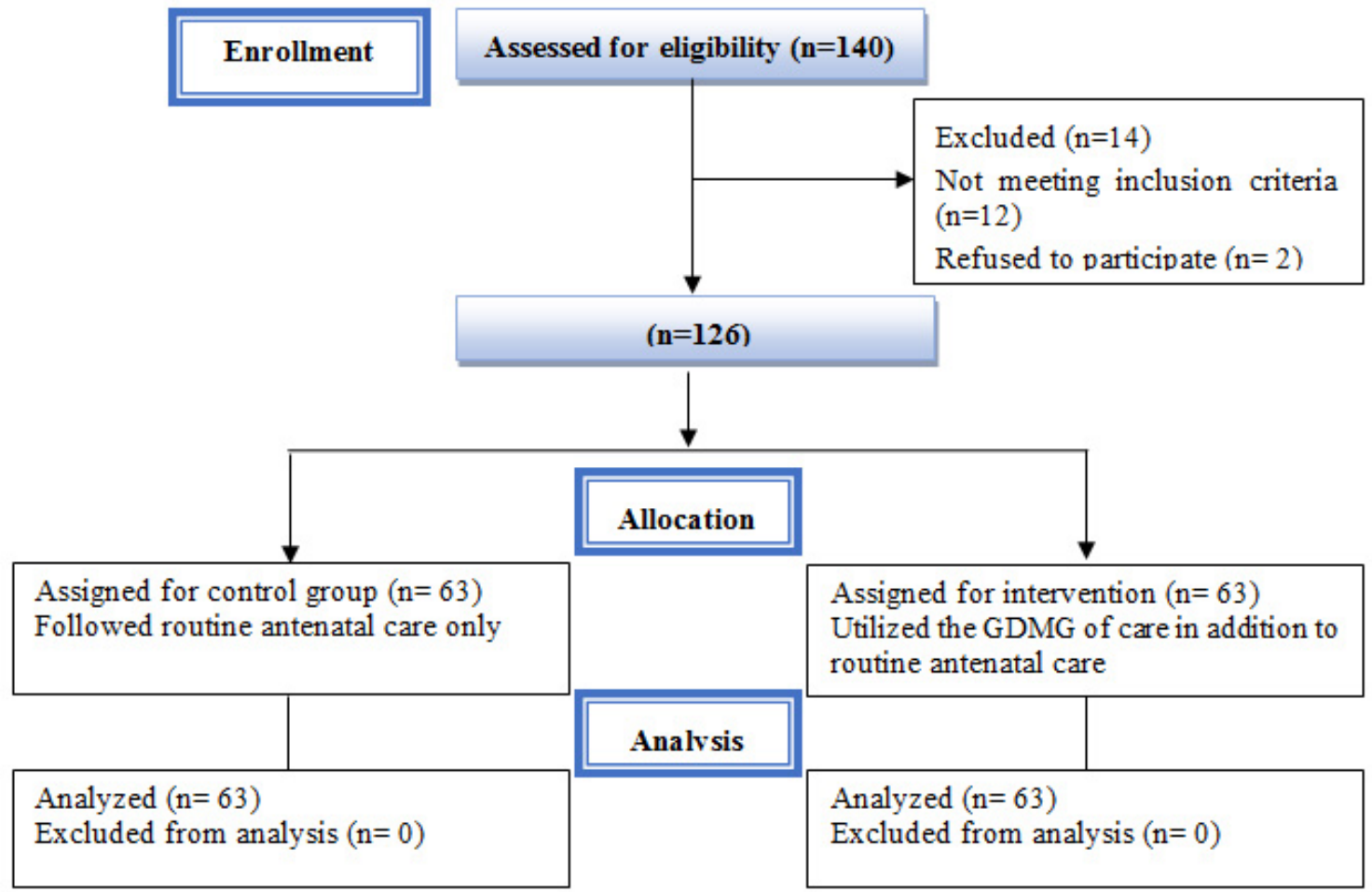

Figure 1. Flowchart of the sample study 


\subsection{Group allocation}

All GDM pregnant women who attended antenatal clinic were invited to participate in the study. About 140 pregnant women with GDM were assessed for eligibility to participate in the current study, 12 woman didn't met the inclusion criteria \& 2 refused to participate in the study. Thus, excluded leaving 126 eligible women divided into equal numbers (63 women for each group). The first 63 pregnant women assigned to control group while the second 63 pregnant women assigned to GDMG group till finishing the sample size (Flowchart of the study sample indicated in Figure $1)$.

\subsection{The tools of data collection}

Three tools were used for data collection; these tools were developed by the researcher as follows:

Tool I: A structured interview schedule

It was designed to collect data about the participant's general characteristics such as (age, educational level, occupation, telephone number, weight, height and Body Mass Index (BMI) and obstetrical history such as (gravidity, parity, gestational age ....etc).

Tool II: Maternal assessment record

It was designed to assess the occurrence maternal complications during pregnancy and childbirth and involved three parts as follows:

Part (1): Maternal Blood Glucose Levels Follow-up Record: Measuring the maternal random blood glucose level.

Part (2): Maternal complications that occurred during pregnancy such as gestational hypertension, preeclampsia, antepartum hemorrhage, preterm labor.

Part (3): Maternal complications that occurred during childbirth to collect information related to the delivery mode, complications that occurred during labor such as prolonged second stage of labor, premature rupture of membranes, perineal laceration and bleeding during third stage of labor.

Tool III: Fetal and Neonatal Assessment Record.

This record was designed to assess the occurrence of fetal \& neonatal complications. It consisted of five parts as follows:

Part (1): to assess the occurrence of fetal complications such as fetal macrosomia, intrauterine growth restriction, congenital malformations, intrauterine fetal death.

Part (2): Apgar score. It was adopted from (Virginia Apgar, 1952). It was performed at the 1 st \& 5 th minutes after birth. It included appearance, pulse, respiratory effort, muscle tone and reflex irritability of the newborn. The results were used to evaluate the neonate's Cardio-respiratory condition after birth.

Part (3): for recording Anthropometric Measurements for neonates such as weight, length, head circumference and chest circumference.

Part (4): to assess the occurrence of neonatal complications such as preterm baby, respiratory distress, Neonatal Intensive Care Unit (NICU) admission and neonatal death.

Part (5): for recording the neonatal random blood glucose level within the first 2 hours after delivery by taking drop of blood from the heel of the neonate.

\subsection{The validity of the tools}

The tools validity was confirmed by a panel of three experts in the specialty of the study: the first expert specialized in obstetric field of medicine and the other two experts specialized in maternity nursing. Based on the expert's recommendations minor modifications were performed.

\subsection{Reliability of the tools}

The reliability test and internal consistency for the questionnaire showed Cronbach's alpha value for tool II $(\alpha=0.835)$ $\&$ for tool III $(\alpha=0.866)$ and hence the questionnaire showed high reliability.

\subsection{Pilot study}

The pilot study was performed on $10 \%$ (13 pregnant women with GDM) of the study sample. The purpose of this pilot study was to test clarity of the questions and statements, feasibility, objectivity and consistency of tools and to detect ambiguity in the study tools. Based on finding of the pilot study, the necessary modifications were done on the study tools. The pilot sample was excluded from the total study sample.

\subsection{Ethical considerations}

Ethical approval was obtained from Research Ethics Committee at the Faculty of Nursing - Mansoura University. Participants were informed that participation in the study was voluntary. They were also informed that each participant has the right to withdraw from the study at any time without any consequences. An informed written consent was taken from all participants after explaining the purpose of the study. The participants were reassured about the Anonymity, privacy, safety \& confidentiality of the collected information throughout the whole study as the tool was given code number instead of taking woman's name. After finishing statistical analysis all sheets were burned. The results were used as a component of the necessary research for doctoral study as well as for future publications and education.

ISSN 2324-7940 E-ISSN 2324-7959 


\subsection{Research process}

This study was conducted through three phases; preparatory, implementation and evaluation of the outcomes.

\subsubsection{Preparatory phase}

In this phase, official agreements were taken from the Ethics Committee of Nursing Faculty and from the director of the Antenatal Clinic of Obstetric and Gynecological Specialty Center at Mansoura University Hospitals. Also, an official permission was obtained from five institutions: International Diabetes Federation, National Institute for Health and Care Excellence, World Health Organization, American Diabetes Association and International Federation of Obstetrics and Gynecology to select items of their guidelines to develop the current guideline.

After that, the study tools were prepared by the researcher after reviewing of the current national and international related literatures, its validity and reliability were tested and the required modifications were done. Then, the researcher prepared the study GDMG after massive review of literature $\&$ previously mentioned guidelines.

The GDMG included information about the definition of GDM, risk factors, sings \& symptoms, maternal and neonatal complications, antepartum care which included instruction related to diet, exercise, insulin therapy, treatment of hypoglycemia, self-monitoring blood glucose level and postpartum care.

Piloting was conducted on thirteen pregnant women with the pre-assigned criteria to test the feasibility of the intervention. The actual field work of the study was conducted for 8 month's period from May 2019 to December 2019.

\subsubsection{Implementation phase}

The researcher attended to the antenatal clinic of obstetric and gynecological specialty center three days/week from 9 a.m. till 12 p.m., firstly the researcher introduced herself to the subjects and their informed consent was taken after explaining the aim of the study. After that, the researcher checked if the subjects met the inclusion criteria of the study, accordingly, the researcher completed the data of structured interview schedule for the study groups.

Random Blood Glucose (RBG) sample was taken as well as anthropometric assessment were measured to each subject in both intervention and control groups, then, the researcher calculated the subjects BMI through the following formula woman's weight in Kilogram divided by height squared in meter BMI = weight in kilogram/(height $)^{2} \cdot{ }^{[8]}$

\subsubsection{Control group}

Control group received the routine care of the antenatal clinic at the obstetric and gynecological specialty center which con- sisted of booking, history taking, physical examination and investigation such as Complete Blood Count (CBC), liver, kidney function tests and urine analysis.

\subsubsection{Intervention group}

At this phase, the items of the developed GDMG were explained for each subject (intervention group) in the form of individualized health education session and each subject was given a chance to discuss any of her concerns as well as answering her questions. Also, each subject was taught insulin self-injection and how to monitor her blood glucose level at self-blood glucose chart using video and PowerPoint presentation. After that, a handout of Arabic version of GDMG was given to the subjects to facilitate the process of education.

After that, the researcher planned with the subjects for subsequent antenatal visits to be one visit every 2 weeks till delivery. At each visit, a subsequent educational sessions reinforced by the researcher for knowledge and self-care measures related to GDM as well as checking the subjects self- blood glucose chart. Also, the researcher took permission from each subject to call her if she missed any of her antenatal visits to follow her progress.

\subsection{Evaluation of the study outcomes}

Three post intervention evaluations were done; the first and the second were at $34 \& 37$ weeks of pregnancy to measure the RBG \& anthropometric measurements and evaluating the study subjects for the occurrence of any complications in both groups such as hypertension, preeclampsia, antepartum hemorrhage and preterm labor. Also, for checking the occurrence of fetal complications as fetal macrosomia, congenital malformations, intrauterine growth restriction and intrauterine fetal death.

While, the third evaluation was at Labor Day in which the subjects of the study groups were instructed to call the researcher at labor time to evaluate their health or presence of complications such as prolonged second stage of labor, genital lacerations and bleeding. Also, for evaluating neonatal condition through recording of Apgar score at the 1st $\& 5$ th minutes, anthropometric measurements of the newborn, measuring neonatal random blood glucose level as well as assessing neonatal complications such as preterm baby, admission to NICU and neonatal death.

\subsection{Statistical analysis}

All statistical analyses were performed using SPSS for windows version 20.0 (SPSS, Chicago, IL). All continuous variables normally distributed and were expressed in mean \pm standard deviation $(S D)$. Categorical data were expressed in number and percentage. The comparisons were determined using Student's $t$ test for two variables with continuous data 
of normal distribution. Chi-square test was used for comparison of variables with categorical data.

\section{Results}

Table 1 presents demographic characteristics of the intervention and the control groups. The mean age of studied groups was almost similar (30.9 vs. 30.8), respectively. The higher percentages of the intervention and control groups had secondary education, were housewives and from the rural area. There was no statistical significant difference between the studied groups concerning age, level of education, occupation and place of residence $(p>.05)$.

Table 1. Frequency distribution of the intervention and the control groups according to their demographic characteristics

\begin{tabular}{|c|c|c|c|c|c|c|}
\hline \multirow{2}{*}{ Demographic characteristics } & \multicolumn{2}{|c|}{ Intervention group $(n=63)$} & \multicolumn{2}{|c|}{ Control group $(n=63)$} & \multicolumn{2}{|c|}{ Chi square test } \\
\hline & No. & $\%$ & No. & $\%$ & $\chi^{2}$ & $p$ \\
\hline \multicolumn{7}{|l|}{ Age (years) } \\
\hline $18<23$ & 2 & 3.2 & 6 & 9.5 & & \\
\hline $23<29$ & 27 & 42.9 & 17 & 27.0 & & \\
\hline $29<35$ & 19 & 30.2 & 27 & 42.9 & & \\
\hline$\geqslant 35$ & 15 & 23.8 & 13 & 20.6 & 5.807 & .121 \\
\hline Mean $\pm S D$ & $30.9 \pm 5.2$ & & $30.8 \pm 5.6$ & & $0.066^{*}$ & .948 \\
\hline \multicolumn{7}{|l|}{ Residence } \\
\hline Urban & 28 & 44.4 & 25 & 39.7 & & \\
\hline Rural & 35 & 55.6 & 38 & 60.3 & 0.293 & .588 \\
\hline \multicolumn{7}{|l|}{ Educational level } \\
\hline Read/Write & 18 & 28.6 & 20 & 31.7 & & \\
\hline Secondary education & 24 & 38.1 & 25 & 39.7 & & \\
\hline High education & 21 & 33.3 & 18 & 28.6 & 0.356 & .837 \\
\hline \multicolumn{7}{|l|}{ Occupational status } \\
\hline House wife & 46 & 73.0 & 47 & 74.6 & & \\
\hline Working & 17 & 27.0 & 16 & 25.4 & 0.041 & .839 \\
\hline
\end{tabular}

Table 2 presents the anthropometric measures of the intervention and the control groups. There was no statistical significant difference between the studied groups concerning the categories of body mass index at baseline assessment (28-32 weeks of gestation). While, there was highly statistical significant difference between two groups concerning the categories of body mass index at 37 weeks of gestation $(p<$ $.001)$.

Table 3 shows that the mean of maternal random blood glucose levels at baseline assessment was $(168.2 \pm 37.7 \& 177.1$ \pm 37.9 ), respectively with no statistical significant difference among the studied groups. On the other hand, there was highly statistical significant difference between both groups in relation to maternal random blood glucose levels at both $34 \& 37$ weeks of pregnancy $(p<.001)$.

Table 4 presents the occurrence of current pregnancy re- lated complications between the intervention and the control groups. Results revealed that, $39.7 \%$ of the women in the intervention group vs. $84.1 \%$ in the control group had complications during the current pregnancy such as gestational hypertension and preeclampsia $(14.3 \% \& 9.5 \%)$, respectively in the intervention group compared with (54\% \& $41.3 \%)$, respectively in the control group. There was highly statistical significant difference between two groups $(p<.001)$.

Table 5 presents the occurrence of maternal complications during Labor between the intervention and the control groups. Data revealed that, $25.6 \%$ of the women in the intervention group vs. $75.0 \%$ in the control group had complications during labor. It was noticed that $20.5 \%$ of the intervention group had birth canal injury compared with $64.3 \%$ of the control group. There was highly statistical significant difference between the studied groups $(p<.001)$. 
Table 2. Frequency distribution of the anthropometric measures for the intervention and the control groups

\begin{tabular}{|c|c|c|c|c|c|c|}
\hline \multirow{2}{*}{ Body Mass Index status } & \multicolumn{2}{|c|}{ Intervention group } & \multicolumn{2}{|c|}{ Control group } & \multicolumn{2}{|c|}{ Chi square test } \\
\hline & No. & $\%$ & No. & $\%$ & $\chi^{2}$ & $p$ \\
\hline $\begin{array}{l}\text { Before intervention (At 28-32 weeks of } \\
\text { pregnancy) }\end{array}$ & $(\mathrm{n}=63)$ & & $(\mathrm{n}=63)$ & & & \\
\hline Height (cm) & $165.9 \pm 4.5$ & & $165.7 \pm 4.5$ & & 0.217 & .829 \\
\hline Body weight (kg) & $79.3 \pm 12.9$ & & $81.8 \pm 13.8$ & & 1.050 & .296 \\
\hline \multicolumn{7}{|l|}{ BMI $\left(\mathrm{kg} / \mathrm{m}^{2}\right)$} \\
\hline Normal & 15 & 23.8 & 12 & 19.0 & & \\
\hline Overweight & 24 & 38.1 & 21 & 33.3 & & \\
\hline Obese & 20 & 31.7 & 24 & 38.1 & & \\
\hline Morbidly obese & 4 & 6.3 & 6 & 9.5 & 1.297 & .730 \\
\hline Mean $\pm S D$ & $28.8 \pm 4.4$ & & $29.8 \pm 4.6$ & & $1.214 *$ & .227 \\
\hline After intervention (At 37 weeks of pregnancy) & $(\mathrm{n}=59)$ & & $(\mathrm{n}=51)$ & & & \\
\hline Height $(\mathrm{cm})$ & $164.3 \pm 4.4$ & & $165.6 \pm 5.0$ & & 1.484 & .141 \\
\hline Body weight (kg) & $82.6 \pm 13.4$ & & $92.1 \pm 13.3$ & & 3.721 & $<.001^{* *}$ \\
\hline \multicolumn{7}{|l|}{$\operatorname{BMI}\left(\mathrm{kg} / \mathrm{m}^{2}\right)$} \\
\hline Normal & 6 & 10.2 & 2 & 3.9 & & \\
\hline Overweight & 20 & 33.9 & 8 & 15.7 & & \\
\hline Obese & 27 & 45.8 & 21 & 41.2 & & \\
\hline Morbidly obese & 6 & 10.2 & 20 & 39.2 & 14.928 & .002 \\
\hline Mean $\pm S D$ & \multicolumn{2}{|c|}{$30.6 \pm 4.5$} & \multicolumn{2}{|c|}{$33.6 \pm 4.4$} & $3.572^{*}$ & $<.001^{* *}$ \\
\hline
\end{tabular}

Note. ${ }^{*} t$ value, Student's $t$ test; ${ }^{* *}$ Highly Statistical Significant at $p<.001$

Table 3. Frequency distribution of the intervention and the control groups according to their random blood glucose levels

\begin{tabular}{|c|c|c|c|c|c|c|}
\hline \multirow{2}{*}{ Maternal RBG* levels } & \multicolumn{2}{|c|}{ Intervention group } & \multicolumn{2}{|c|}{ Control group } & \multicolumn{2}{|c|}{ Chi square test } \\
\hline & No. & $\%$ & No. & $\%$ & $\chi^{2}$ & $p$ \\
\hline Before intervention (At 28-32 wks) & $(\mathrm{n}=63)$ & & $(\mathrm{n}=63)$ & & & \\
\hline Normal (80-140 mg/dl) & 11 & 17.5 & 7 & 11.1 & & \\
\hline High (> $140 \mathrm{mg} / \mathrm{dl})$ & 52 & 82.5 & 56 & 88.9 & 1.307 & .309 \\
\hline Mean $\pm S D$ & $168.2 \pm 37.7$ & & $177.1 \pm 37.9$ & & 1.321 & .189 \\
\hline $\begin{array}{l}\text { After intervention (At } 37 \text { weeks of } \\
\text { pregnancy) }\end{array}$ & $(\mathrm{n}=63)$ & & $(\mathrm{n}=57)$ & & & \\
\hline Normal & 59 & 93.7 & 0 & 0.0 & & \\
\hline High & 4 & 6.3 & 57 & 100.0 & 105.012 & $<.001^{* *}$ \\
\hline Mean $\pm S D$ & $113.2 \pm 14.0$ & & $193.6 \pm 38.8$ & & 15.395 & $<.001^{* *}$ \\
\hline At 37 weeks & $(\mathrm{n}=59)$ & & $(\mathrm{n}=51)$ & & & \\
\hline Normal & 59 & 100.0 & 0 & 0.0 & & \\
\hline High & 0 & 0.0 & 51 & 100.0 & 110.000 & $<.001^{* *}$ \\
\hline Mean $\pm S D$ & $102.3 \pm 10.1$ & & $202.4 \pm 37.2$ & & 19.856 & $<.001^{* *}$ \\
\hline
\end{tabular}


Table 4. Frequency distribution of the intervention and the control groups according to current pregnancy related complications

\begin{tabular}{|c|c|c|c|c|c|c|}
\hline \multirow{2}{*}{ Items } & \multicolumn{2}{|c|}{ Intervention group $(n=63)$} & \multicolumn{2}{|c|}{ Control group $(n=63)$} & \multicolumn{2}{|c|}{ Chi square test } \\
\hline & No. & $\%$ & No. & $\%$ & $\chi^{2}$ & $p$ \\
\hline \multicolumn{7}{|c|}{ Presence of pregnancy related complications } \\
\hline No & 38 & 60.3 & 10 & 15.9 & & \\
\hline Yes & 25 & 39.7 & 53 & 84.1 & 26.385 & $<.001$ \\
\hline Gestational hypertension & 9 & 14.3 & 34 & 54.0 & 22.065 & $<.001^{* * *}$ \\
\hline Preeclampsia & 6 & 9.5 & 26 & 41.3 & 16.755 & $<.001^{* * *}$ \\
\hline Antepartum hemorrhage & 2 & 3.2 & 3 & 4.8 & 0.208 & .648 \\
\hline Preterm labor & 4 & 6.3 & 12 & 19.0 & 4.582 & $.032^{*}$ \\
\hline PROM & 8 & 12.7 & 22 & 34.9 & 8.575 & $.003^{*}$ \\
\hline Polyhydramnios & 8 & 12.7 & 20 & 31.7 & 6.612 & $.010^{*}$ \\
\hline Genital tract infection & 6 & 9.5 & 9 & 14.3 & 0.681 & .409 \\
\hline
\end{tabular}

Note. ${ }^{*}$ Statistical Significant at $p<.05 ;{ }^{* *}$ Highly Statistical Significant at $p<.001$

Table 5. Frequency distribution of the intervention and the control groups according to the occurrence of maternal complications during labor

\begin{tabular}{|c|c|c|c|c|c|c|}
\hline \multirow{2}{*}{ Items } & \multicolumn{2}{|c|}{ Intervention group $(n=39)$} & \multicolumn{2}{|c|}{ Control group $(n=28)$} & \multicolumn{2}{|c|}{ Chi square test } \\
\hline & No. & $\%$ & No. & $\%$ & $\chi^{2}$ & $p$ \\
\hline \multicolumn{7}{|l|}{ Labor related complications } \\
\hline No & 29 & 74.4 & 7 & 25.0 & & \\
\hline Yes & 10 & 25.6 & 21 & 75.0 & 15.972 & $<.001$ \\
\hline Prolonged $2^{\text {nd }}$ stage of labor & 4 & 10.3 & 14 & 50.0 & 13.103 & $<.001^{* *}$ \\
\hline Maternal distress & 0 & 0.0 & 2 & 7.1 & 2.871 & .090 \\
\hline Genital tract laceration & 8 & 20.5 & 18 & 64.3 & 13.151 & $<.001^{* *}$ \\
\hline Postpartum hemorrhage & 5 & 12.8 & 10 & 35.7 & 4.916 & $.027^{*}$ \\
\hline
\end{tabular}

Note. ${ }^{*}$ Statistical Significant at $p<.05 ;{ }^{* *}$ Highly Statistical Significant at $p<.001$

Table 6. Frequency distribution of neonatal complications among the intervention and the control groups

\begin{tabular}{|c|c|c|c|c|c|c|}
\hline \multirow{2}{*}{ Items } & \multicolumn{2}{|c|}{ Intervention group $(n=61)$} & \multicolumn{2}{|c|}{ Control group $(n=59)$} & \multicolumn{2}{|c|}{ Chi square test } \\
\hline & No. & $\%$ & No. & $\%$ & $\chi^{2}$ & $p$ \\
\hline \multicolumn{7}{|c|}{ Neonatal complications } \\
\hline No & 40 & 65.6 & 27 & 45.8 & & \\
\hline Yes & 21 & 34.4 & 32 & 54.2 & 4.773 & $.029^{*}$ \\
\hline Prematurity & 4 & 6.6 & 12 & 20.3 & 4.930 & $.026^{*}$ \\
\hline Macrosomic baby & 6 & 9.8 & 15 & 25.4 & 5.047 & $.025^{*}$ \\
\hline Respiratory distress & 9 & 14.8 & 18 & 30.5 & 4.269 & $.039^{*}$ \\
\hline Congenital anomaly & 2 & 3.3 & 4 & 6.8 & 0.774 & .379 \\
\hline Admission to NICU & 10 & 16.4 & 20 & 33.9 & 4.901 & $.027^{*}$ \\
\hline Neonatal death & 2 & 3.3 & 6 & 10.2 & 2.289 & 0.130 \\
\hline
\end{tabular}

Note. "Statistical Significant at $p<.05$; NB: 2 IUFD in the intervention group and 4 IUFD in the control group 
Table 6 presents the frequency distribution of neonatal complications among the intervention and the control groups. Results revealed that, $34.4 \%$ of women in the intervention group had neonatal complications compared with $54.2 \%$ of the control group. There was statistical significant difference among studied groups.

\section{Discussion}

Gestational Diabetes Mellitus (GDM) substantially increases the risk of adverse health effects on both women and their offspring, thus create highly medical costs for prenatal, intranatal as well as postnatal care. Therefore, pregnancy is an ideal time for providing health education to women with GDM, because health education is the first step of diabetes management and providing women with accurate knowledge, skills and actions to cope with the practical aspects of selfcare measures regarding GDM to improve fetal and maternal outcomes. ${ }^{[17]}$

The current study aimed to evaluate the effect of utilizing developed gestational diabetes mellitus guideline on pregnancy and childbirth outcomes. The study hypothesis was supported by the study results as there was a highly statistical significant difference between the intervention and the control groups regarding maternal, fetal \& neonatal outcomes.

Guo et al. ${ }^{[18]}$ reported that, educational intervention regarding diet and exercise has a positive impact on healthy weight gain in pregnant women with GDM which is consistent with the findings of the current study as there was no statistical significant difference among the studied groups in relation to body mass index at baseline assessment (28-32 weeks of gestation). On the contrary, there was a highly statistical significant difference at 37 weeks of gestation (see Table 2). This may be due to the subjects' compliance to the dietary management and commitment to nutritional counseling for maintaining normal fetal growth, maternal health and optimal glycemic control throughout the pregnancy.

Such findings are supported by Azzam et al ${ }^{[8]}$ who studied the effect of GDM educational intervention on pregnancy outcomes and reported that, there was a statistical significant difference between the intervention and control groups regarding to the mean body weight $\&$ mean BMI before intervention compared to at 37 weeks' of pregnancy after intervention.

In the same line ${ }^{[19]}$ who conducted a randomized controlled trial to evaluate the effectiveness of diet and exercise on preventing excessive weight gain during pregnancy, found that, women who received diet \& exercise education were more likely to experience low weight gain than those who did not.
Another study by O'BrienC et al. ${ }^{[20]}$ about impact of maternal education on response to lifestyle interventions to reduce gestational weight gain reported that, there was a statistical significant reduction in weight gain for diet based interventions compared with those in the control group.

Several studies showed significantly lower Oral Glucose Tolerance Test (OGTT) in physically active women as physical activity improves insulin sensitivity and reduces both fasting and postprandial glucose concentrations in women with GDM. ${ }^{[21,22]}$ The current study findings showed that, there was no statistical significant difference in the maternal random blood glucose levels baseline assessment among the studied groups. On the other hand, there was a highly statistical significant difference among the studied groups at both $34 \& 37$ weeks of pregnancy (see Table 3). Such findings may be contributed to well-balanced eating module aimed to maintaining and controlling blood glucose level through offering an individualized meal plan which urges to eat snacks \& timing meals as well as consuming a variety of nutrients.

This result is in concurrent with El Toony et al. ${ }^{[23]}$ who stated that, the blood glucose level significantly controlled by medical nutritional therapy and exercise in their study about the effectiveness of an educational program for women with GDM. Another study by Allehdan et al. ${ }^{[24]}$ who studied the effect of dietary and exercise interventions on glycemic control, maternal and neonatal outcomes in women with GDM reported that, the combination of diet and exercise interventions controls fasting \& postprandial blood glucose level.

Moreover, Azzam et al. and Zandinava et al. ${ }^{[8,25]}$ found that, there was a statistical significant difference among the intervention and the control groups regarding the decrease of the mean blood glucose levels after two weeks' of intervention \& 37 weeks' of pregnancy.

Ming et al. ${ }^{[26]}$ reported that, GDM can affect the health of both mothers and their offspring due to transient abnormalities in carbohydrate metabolism as women with GDM are at higher risk for experiencing preterm birth, polyhydramnios, infection, fetal macrosomia, fetal malformation and fetal demise than normally pregnant women. However, several studies have shown that, the pregnancy outcomes in pregnant women and their fetus/newborns can be improved through careful monitoring and controlling of blood glucose level. Therefore, early diagnosis and active intervention are of clinical significance for pregnant women with GDM. ${ }^{[27,28]}$

The present study findings revealed that, $39.7 \%$ of the women in the intervention group vs. $84.1 \%$ in the control group had complications during the current pregnancy. There was a statistically significant reduction in the incidence of gestational 
hypertension, preeclampsia, preterm labor and polyhydramnious during pregnancy (see Table 4). This may be attributed to the controlled blood glucose level as proved by the study findings (see Table 5) which in turn reduces the risk of shortterm GDM complications.

This result supported by Brown et al. ${ }^{[29]}$ who studied lifestyle interventions for the management of women with GDM and concluded that, lifestyle interventions were associated with a reduction in the risk of preterm labor.

El Toony et al. ${ }^{[23]}$ Observed that, the educated group about GDM had significantly less incidence of pre-eclampsia and hydramnios than control group. Also, a systematic review by Carolan-Olah et al. ${ }^{[30]}$ about the efficacy of educational and intervention programs for GDM management showed a significant reduction in hypertensive disorders rates and better pregnancy outcomes.

Moreover, this result is in agreement with several studies which concluded that, the effective controlling of blood glucose level was associated with better pregnancy and neonatal outcomes in women with GDM. Also, they reported that, the incidence of preeclampsia, PIH and polyhydramnios were much higher in the control group than the interven- tion group. ${ }^{[31,32]}$

Contradictory to the current study findings, ${ }^{[33]}$ Brown conducted a randomized controlled trial comparing an exercise intervention with standard care in pregnant women diagnosed with GDM and reported that, there was no difference between women in the exercise group and those in the control group regarding the risk of developing pre-eclampsia and preterm labor. Also, Carolan-Olah et al. ${ }^{[34]}$ found no statistical difference regarding maternal blood pressure among the studied groups in their web-based educational intervention for women with GDM.

Wang et al. ${ }^{[35]}$ reported in their review about the incidence of adverse effects associated with GDM in low and middle income countries that, cesarean delivery was the highest rate (87.1\%) compared to other adverse effects in women with GDM which is consistent with the findings of the current study as there was a statistical significant difference among the studied groups regarding the mode of delivery as the control group had higher rate of cesarean section deliveries compared to the intervention group (see Figure 2). This finding might be attributed to the hospital policy which recommends that women with GDM delivered by CS.

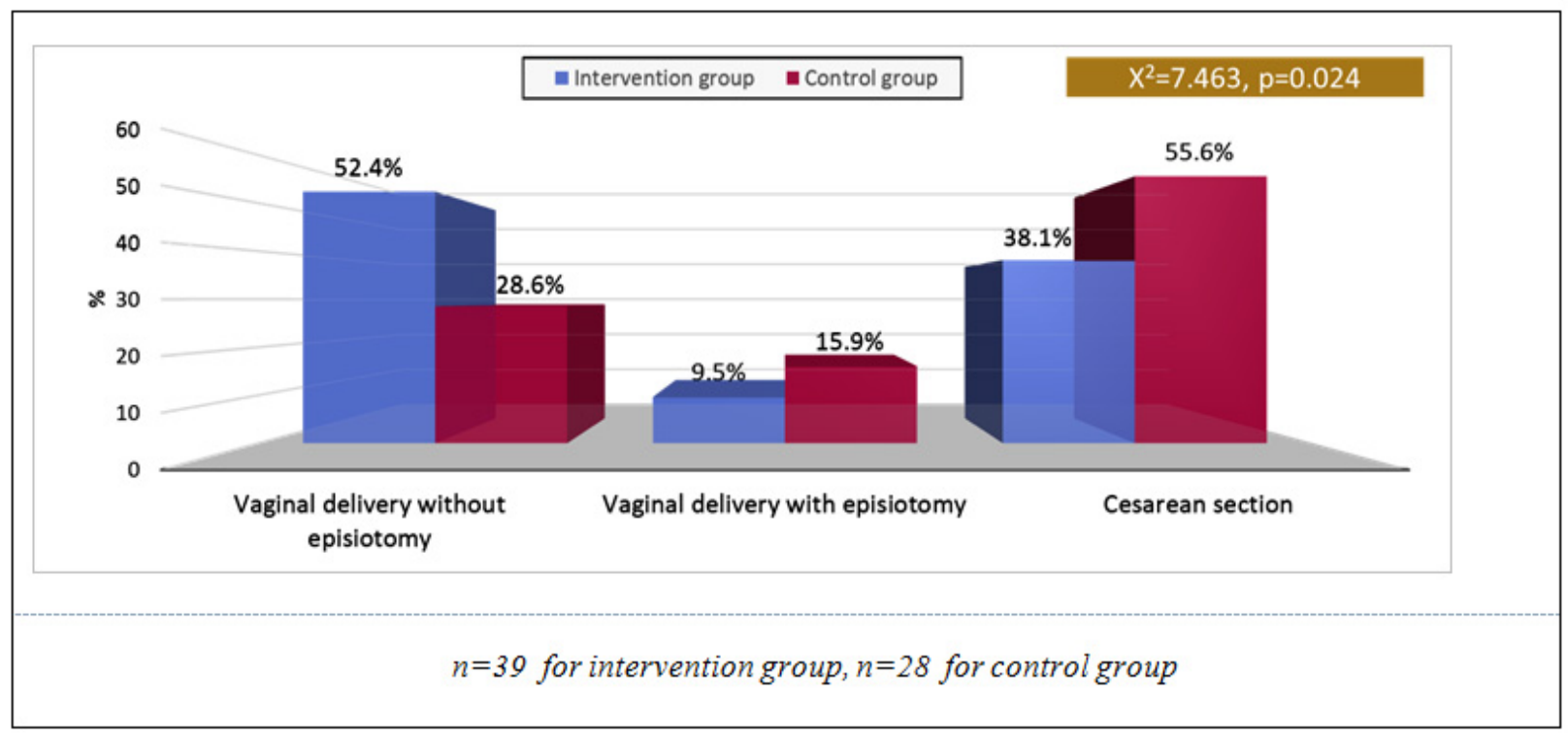

Figure 2. Comparison between the intervention and the control groups in relation to current mode of delivery

This finding is in concurrent with Azzam et al. ${ }^{[8]}$ who reported that, there was a highly statistical significant difference among the studied groups in relation to the impact of the GDM educational intervention on mode of delivery as more than three quarters of control group had CS. Again, Zhao et al. and Mylonas et al. ${ }^{[32,36]}$ showed that, the incidence of cesarean section in the control group was significantly higher than that in the intervention group.

On the other hand, these findings contradict with the findings of Kolivand et al. and El Toony et al. ${ }^{[10,23]}$ who stated that, there was no statistical significant difference regarding the rate of cesarean section among the studied groups. The researchers attributed their findings as some of obstetricians prefer to deliver their cases via CS without apparent medical 
cause.

GDM is linked to several complications during labor that can lead to substantial maternal morbidity and mortality as obstructed labor, bleeding and perineal laceration. ${ }^{[11]}$ The current study revealed that, only one quarter of the women who delivered normally in the intervention group vs. three quarters of the control group had complications during labor as prolonged second stage of labor, genital tract laceration and postpartum hemorrhage (see Table 5).

These findings are in congruent with El-Nagar et al. and Liu et al. ${ }^{[9,37]}$ who found that, the women who received educational intervention about GDM exhibit lower in the incidence of postpartum hemorrhage suggesting that educational inter- vention can significantly improve childbirth outcomes.

Contradictory to the current study findings, ${ }^{[29,32]}$ there was no difference of perineal trauma and postpartum hemorrhage rates among women in the lifestyle intervention group and the control group.

Regarding neonatal Apgar score at the 1st \& 5th minute after birth of the studied groups. There was a statistical significant difference among the studied groups at the 1 st $\& 5$ th minute after birth as more than half of the neonates have better Apgar score than the control group (see Figure 3). Several studies support the current study finding in which Apgar scores after birth were significantly better in the intervention groups. ${ }^{\left[{ }^{8-10]}\right.}$

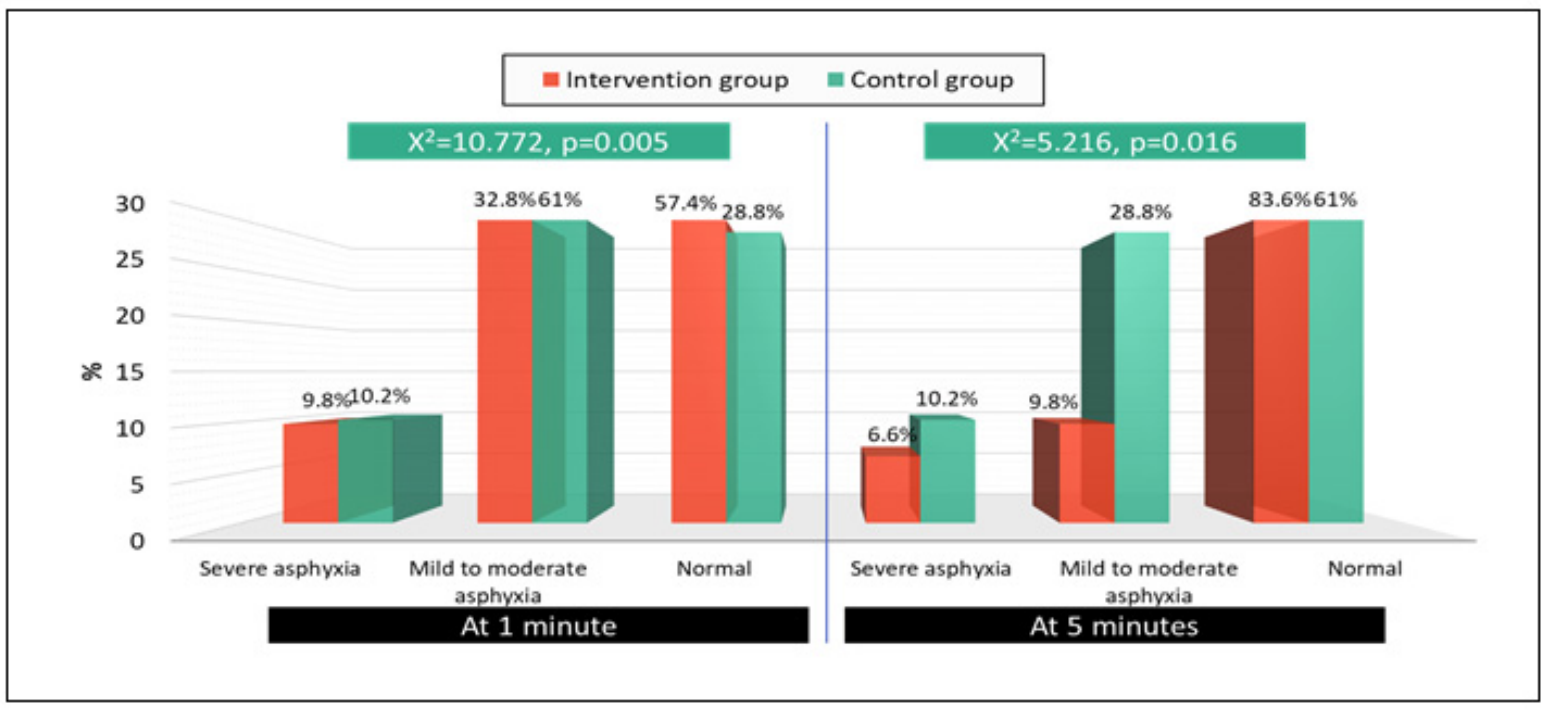

Figure 3. Comparison between the Intervention and the Control Groups in Relation to the Neonatal Apgar Score at the 1st $\&$ 5th Minute after Birth

In contrast, Gasim ${ }^{[38]}$ and Şen ${ }^{[39]}$ who concluded that, Apgar scores showed no significant difference among the studied groups. The researchers revealed that, this discrepancy might be related to the differentiate policies for observing and caring of the neonates among these hospitals. ${ }^{[38,39]}$

Women with GDM are at high risk for developing neonatal complications and increase in admission rates of NICU due to macrosomia, hypoglycemia and respiratory distress syndrome which lead to increased rates of perinatal mortality. Even though, numerous studies have reported that, self-care educational interventions have a significant positive effect on improving neonatal outcomes. ${ }^{[40,41]}$

The present study revealed that, about $34.4 \%$ of women in the intervention group had neonatal complications compared with $54.2 \%$ of the control group. There was a statistical significant reduction in the occurrence of neonatal compli- cations in the intervention group as prematurity, respiratory distress syndrome and NICU admission rate (see Table 6).

These results are in consistent with previous reports ${ }^{[42]}$ about the impact of controlling the blood sugar on neonatal outcomes with GDM as showed that, the controlling of blood glucose level significantly reduces the incidence of prematurity, low birth weight and neonatal respiratory distress syndrome.

Another study by El-Nagar et al. ${ }^{[9]}$ concluded that, there was a statistical significant difference among the studied groups as more than three quarters of women in the intervention group experienced no neonatal complications compared to only one tenth of the control group. Also, they added that, the most frequent rate of neonatal complications founded in the control group were hypoglycemia, respiratory distress syndrome and birth trauma. 
Similarly, a study by Elshair et al. ${ }^{[43]}$ about the impact of educational program for GDM, pointed out that, the incidence of neonatal complications in their intervention group were lower than the control group. Indicating that health educational intervention can significantly improve perinatal health.

The newborns of diabetic mothers are delivered with hypoglycemia as a result of maternal hyperglycemia. Also, it was reported that the neonatal hypoglycemia mostly occurs at the first to the second hour after birth without obvious symptoms and sometimes undetected consequently, severe neurological complications or even death can be developed if glucose was not supplemented timely. Therefore, the routine screening of blood glucose should be carried out for neonates during neonatal periods to prevent neonatal hypoglycemia and reduce irreversible damage to the nervous system. ${ }^{[44]}$

The current study findings revealed that, there was a statistical significant reduction in the incidence of neonatal hypoglycemia in the intervention group (see Figure 4). This finding is in concurrent with Ouyang et al. ${ }^{[42]}$ who reported that, the control of blood glucose level significantly reduced the incidence of neonatal hypoglycemia.

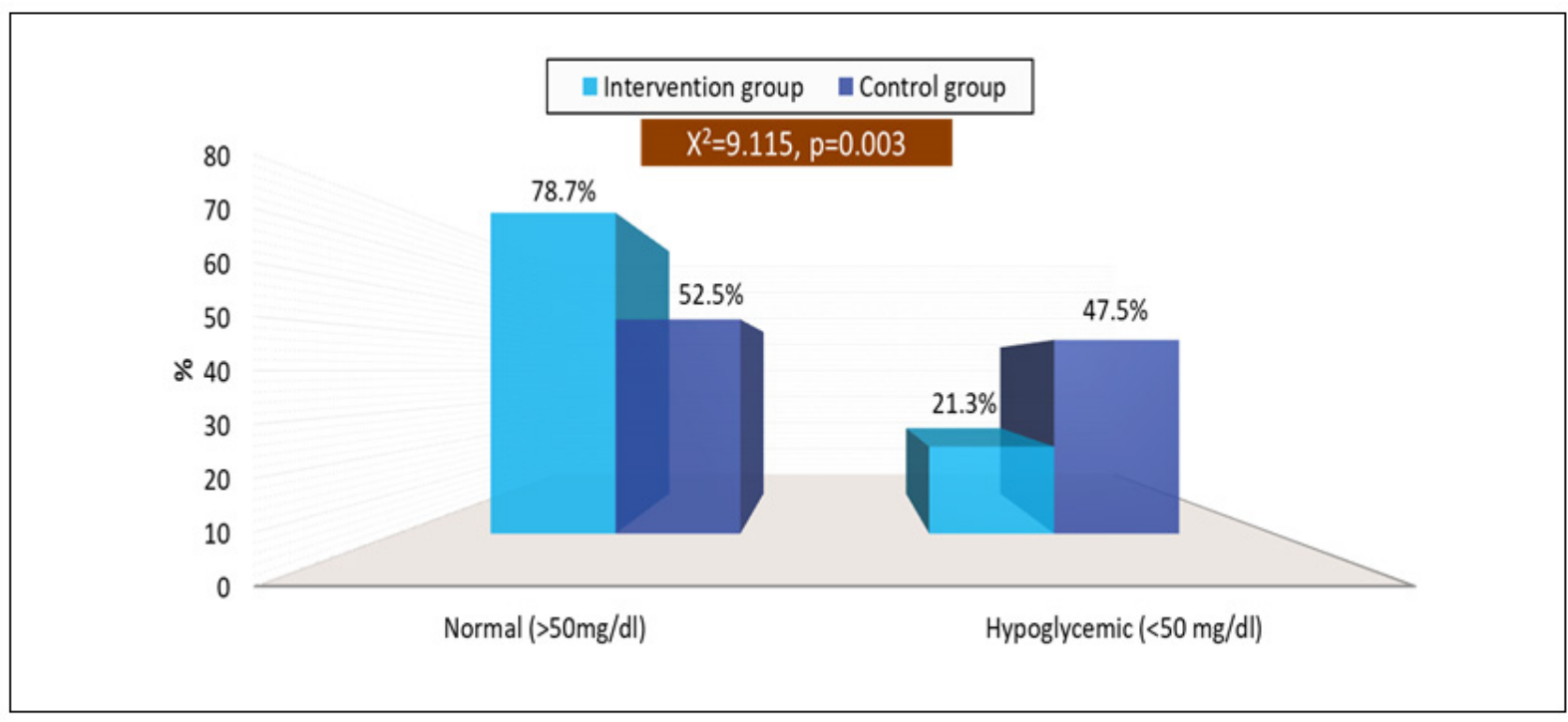

Figure 4. Comparison between the Intervention and the control groups in relation to the neonatal random blood glucose level after birth

At the same line the finding of Azzam et al. ${ }^{[8]}$ who reported that, only seven and one tenth of the neonates in the intervention group had hypoglycemia compared with more than half of the neonates in the control group with highly statistical significant difference among both groups. Also, Guo et al. and Liu et al. ${ }^{[18,37]}$ reported a significant decrease in the incidence of neonatal hypoglycemia among studied groups.

In contrast to these findings, ${ }^{[33]}$ there is no evidence for developing neonatal hypoglycemia among the infants who exposed to a lifestyle intervention and those who exposed to routine care. The researchers attributed their results to abnormal defect of beta cell and excess adiposity of fetal hyperinsulinemia that increases insulin production.

Fortunately, health education guideline given to the intervention group about GDM, the fear from complications and fear from serious threat to health were powerful incentives that enforce the women to follow the strict care regimen to avoid complications and adverse outcomes.
Accordingly, empowering women with knowledge regarding GDM through health educational guideline enables them to seek care, follow medical procedures and participate in health education programs. Knowledge and awareness about GDM will be translated to improve their self-care measures and increase their commitment with the care regimen, which ultimately contributed to complications reduction. So, the study findings proved that the health educational guidelines are necessary step for better management of GDM to improve pregnancy outcomes for the woman and her offspring.

\section{Conclusions}

Based on the present study findings, It was concluded that, utilization of GDM guideline plays an important role in raising pregnant women's awareness regarding GDM and its proper management in order to reduce its burden for both the mother and her fetus. Also, it is important for the GDM educational sessions to be individualized for better client educator experience. So, the study findings elaborate that, preg- 
nant women with GDM who utilized the developed GDMG had better maternal \& neonatal outcomes than those who did not utilize it.

\section{RECOMMENDATIONS}

Based on the current study findings, the following can be recommended:

- Antenatal screening of GDM is very essential for early detection and management in order to improve maternal, fetal and neonatal outcomes.

- Maternity nurses should include GDM guidelines in routine antenatal health education classes to raise awareness of pregnant women regarding effective GDM management to improve their pregnancy outcomes.

- A manual GDM guideline should be provided to all pregnant women with GDM at hospitals and $\mathrm{MCH}$ centers for better lifestyle changes \& maintaining selfmanagement regimen as well as better pregnancy outcomes.

- GDM guidelines should be provided for maternity nurses and other health care worker to update their knowledge on GDM management strategies.

\section{ACKNOWLEDGeMENTS}

We would like to thank the obstetricians, nurses and women at antenatal clinic of obstetric and gynecological specialty center at Mansoura university hospital for their help in conducting the study and without whom the study could not have been achieved.

\section{Conflicts of InTEREST Disclosure}

The authors declare they have no conflicts of interest.

\section{REFERENCES}

[1] Elbeltagy ES, Hassan SI, Khedr NF. Association of Cesarean Delivery with Occurrence of Placenta Previa. IOSR Journal of Nursing and Health Science. 2017; 6(4): 1-9. https://doi.org/10.116 $48 / j$. ajns . 20170603.15

[2] Mukerji G, Bacon S, Feig DS. Gestational Diabetes and Type 2 Diabetes During Pregnancy. In Maternal-Fetal and Neonatal Endocrinology. Academic Press; 2020. 371-388 p. https://doi.org/10.1 016/B978-0-12-814823-5.00022-2

[3] Wang X, Tingting D. Women's experiences of gestational diabetes mellitus: A descriptive review. 2019.

[4] Khanpaye A, Abdoullahi A, Riahipour B, et al. Evaluation of Knowledge, Attitude and Performance Regarding Gestational Diabetes Mellitus in Southwest of Iran. Journal of Pharmaceutical Research International. 2019; 1-6. https ://doi .org/10.9734/jpri/201 9/v28i430207

[5] Craig L, Sims R, Glasziou P, et al. Women's experiences of a diagnosis of gestational diabetes mellitus: a systematic review. BMC Pregnancy and Childbirth. 2020; 20(1): 76. PMid: 32028931. https://doi.org/10.1186/s12884-020-2745-1

[6] Nasiri-Amiri F, Sepidarkish M, Shirvani MA, et al. The effect of exercise on the prevention of gestational diabetes in obese and overweight pregnant women: a systematic review and meta-analysis. Diabetology \& Metabolic Syndrome. 2019; 11(1): 72. PMid: 31467594. https://doi.org/10.1186/s13098-019-0470-6

[7] Hull B. Comparison of Confidence in Diabetes Control Between Women Diagnosed with Gestational Diabetes and Women Diagnosed with Diabetes Outside of Pregnancy in California. 2020. Available from: http://hdl.handle.net/10211.3/215882

[8] Azzam H, El Sharkawy N. Effect of Gestational Diabetes Mellitus Health Education Module on Pregnancy Outcomes. World Journal of Nursing Sciences. 2015; 1(3): 76-88.

[9] El-Nagar AE, Ahmed MH, Abo-Freikha A, et al. Effect of Implementation of Health Educational Guidelines on Maternal and Neonatal Outcomes among Women with Gestational Diabetes Mellitus.
Tanta Scientific Nursing Journal. 2019; 17(2): 148-182. https: //doi.org/10.21608/tsnj.2019.71543

[10] Kolivand M, Rahimi MA, Keramat A, et al. Effect of a new self-care guide package on maternal and neonatal outcomes in gestational diabetes: A randomized control trial. 2019; 11(2): 139-147. PMid: 30022620. https://doi.org/10.1111/1753-0407.12827

[11] Cunningham F, Leveno K, Bloom S, et al. Diabetes mellitus. In: Williams Obstetrics, 25th edn. McGraw Hill, New York; 2018; $1357-$ $92 \mathrm{p}$.

[12] Nollino L, Marcon ML, Kiwanuka E, et al. Can Nurse-Based Management Screening Ensure Adequate Outcomes in Patients With Gestational Diabetes? A Comparison of 2 Organizational Models. Quality Management in Healthcare. 2019; 28(1): 56-62. PMid: 30586123 https://doi.org/10.1097/QMH.0000000000000202

[13] WHO Mortality Database [online database]. Geneva: World Health Organization; Accessed 12 January 2016. Available from: http://apps.who.int/healthinfo/statistics/mor tality/causeofdeathquery/

[14] Zhu Y, Zhang C. Prevalence of gestational diabetes and risk of progression to type 2 diabetes: a global perspective. Current Diabetes Reports. 2016; 16(1): 7. PMid: 26742932. https://doi.org/10 $.1007 / \mathrm{s} 11892-015-0699-\mathrm{x}$

[15] Khalil NA, Fathy WM, Mahmoud NS. Screening for gestational diabetes among pregnant women attending a rural family health center-Menoufia governorate-Egypt. Journal of Family Medicine and Health Care. 2017; 3(1): 6-11. https://doi.org/10.11648/j.j fmhc. 20170301.12

[16] Al-Nsour M. Consequences of gestational diabetes and risk factors in Jordan: results of the 2017 Jordan behavioral risk factor surveillance survey. Preventing Chronic Disease J. 2017; 9(1): 25-87.

[17] Osuagwu UL, Fuka F, Agho K, et al. Adverse Maternal Outcomes of Fijian Women with Gestational Diabetes Mellitus and the Associated Risk Factors. Reproductive Sciences. 2020; 1-9. PMid: 32548804. https://doi .org/10.1007/s43032-020-00222-6

[18] Guo H, Zhang Y, Li P, et al. Evaluating the effects of mobile health intervention on weight management, glycemic control and pregnancy 
outcomes in patients with gestational diabetes mellitus. Journal of Endocrinological Investigation. 2019; 42(6): 709-714. PMid: 30406378. https ://doi .org/10.1007/s40618-018-0975-0

[19] Muktabhant B, Lawrie TA, Lumbiganon P, et al. Diet or exercise, or both, for preventing excessive weight gain in pregnancy. Cochrane Database of Systematic Reviews. 2015(6). PMid: 26068707. https : //doi.org/10.1002/14651858.CD007145.pub3

[20] O'BrienC, Segurado R, Geraghty AA, et al. Impact of maternal education on response to lifestyle interventions to reduce gestational weight gain: individual participant data meta-analysis. BMJ Open. 2019; 9(8): e025620. PMid: 31375602. https ://doi.org/10.1 136/bm jopen-2018-025620

[21] Barakat R, Refoyo I, Coteron J, et al. Exercise during pregnancy has a preventative effect on excessive maternal weight gain and gestational diabetes. A randomized controlled trial. Brazilian Journal of Physical Therapy. 2018. PMid: 30470666. https://doi .org/10.1016/j . bjpt.2018.11.005

[22] Lantaff R, Ward R, Griffin S, et al. Women's views concerning lifestyle changes to reduce risk of developing type 2 diabetes after gestational diabetes: A systematic review, qualitative synthesis and recommendations for practice. 2019.

[23] El Toony LF, Khalifa WA, Ghazaly OM. Assessing the effectiveness of an educational program for patients with gestational diabetes in Assiut University. Egyptian Journal of Obesity, Diabetes and Endocrinology. 2018; 1(4): 17. https ://doi.org/10.4103/ejode. ejode_29_17

[24] Allehdan SS, Basha AS, Asali FF, et al. Dietary and exercise interventions and glycemic control and maternal and newborn outcomes in women diagnosed with gestational diabetes: Systematic review. Diabetes \& Metabolic Syndrome: Clinical Research \& Reviews. 2019. PMid: 31405707. https ://doi.org/10.1016/j.dsx.2019.07. 040

[25] Zandinava H, Shafaei FS, Charandabi SMA, et al. Effect of educational package on self-care behavior, quality of life, and blood glucose levels in pregnant women with gestational diabetes: a randomized controlled trial. Iranian Red Crescent Medical Journal. 2017; 19(4). https : //doi.org/10.5812/ircm j . 44317

[26] Ming WK, Ding W, Zhang CJ, et al. The effect of exercise during pregnancy on gestational diabetes mellitus in normal-weight women: a systematic review and meta-analysis. BMC Pregnancy and Childbirth. 2018; 1(18): 1-9. PMid: 30419848. https://doi .org/10.1 186/s12884-018-2068-7

[27] Hosseini E, Janghorbani M, Shahshahan Z. Comparison of risk factors and pregnancy outcomes of gestational diabetes mellitus diagnosed during early and late pregnancy. Midwifery. 2018; 66: 64 69. PMid: 30130677. https://doi.org/10.1016/j.midw. 201 8.07 .017

[28] Wan CS, Nankervis A, Teede H, et al. Dietary intervention strategies for ethnic Chinese women with gestational diabetes mellitus: A systematic review and meta-analysis. Nutrition \& Dietetics. 2019; 76(2): 211-232. PMid: 30938046. https : //doi .org/10.1111/1747-0 080.12524

[29] Brown J, Alwan NA, West J, et al. Lifestyle interventions for the treatment of women with gestational diabetes. Cochrane Database of Systematic Reviews. 2017(5). https : //doi.org/10.1002/1465 1858. CD011970.pub2

[30] Carolan-Olah MC. Educational and intervention programmes for gestational diabetes mellitus (GDM) management: An integra- tive review. Collegian. 2016; 23(1): 103-114. PMid: 27188046 https://doi.org/10.1016/j.colegn.2015.01.001

[31] Kanani M, Leuva B. A study of glycemic control with diet in women with gestational diabetes mellitus. Int J Reprod Contracept Obstet Gynecol. 2017; 6(8): 3428-3433. https://doi.org/10.18203/2 320-1770. ijrcog20173457

[32] Zhao L, Zhang Y, Gu Z, et al. Effects of effective blood glucose control on pregnancy outcomes and neonatal complications in pregnant women with gestational diabetes. International Journal of Clinical and Experimental Medicine. 2019; 12(4): 4387-4391.

[33] Brown J, Ceysens G, Boulvain M. Exercise for pregnant women with gestational diabetes for improving maternal and fetal outcomes. Cochrane Database of Systematic Reviews. 2017(6). https : //doi.org/10.1002/14651858.CD012202.pub2

[34] Carolan-Olah M, Sayakhot P. A randomized controlled trial of a web-based education intervention for women with gestational diabetes mellitus. Midwifery. 2019; 68: 39-47. PMid: 30343264. https://doi.org/10.1016/j.midw.2018.08.019

[35] Wang Z, Kanguru L, Hussein J, et al. Incidence of adverse outcomes associated with gestational diabetes mellitus in low-and middleincome countries. International Journal of Gynecology \& Obstetrics. 2013; 121(1): 14-19. PMid: 23321368. https://doi.org/10.1 016/j.ijgo.2012.10.032

[36] Mylonas I, Friese K. Indications for and risks of elective cesarean section. Deutsches Ärzteblatt International. 2015; 112(29-30): 489. PMid: 26249251. https://doi.org/10.3238/arztebl. 2015 .0489

[37] Liu J, Xie X, Guo Y. Effects of health education intervention at gestation period on pregnancy outcome of diabetes mellitus patients. Kanani, M., \& Leuva, B. (2017). A study of glycemic control with diet in women with gestational diabetes mellitus. Int J Reprod Contracept Obstet Gynecol. 2017; 6: 3428. https://doi.org/10.1 8203/2320-1770. ijrcog20173457

[38] Gasim T. Gestational diabetes mellitus: maternal and perinatal outcomes in 220 Saudi women. Oman Medical Journal. 2012; 27(2): 140-144. PMid: 22496940. https ://doi .org/10.5001/omj . 20 12.29

[39] Şen E, Şirin A. The Effect of Gestational Diabetes Mellitus Training upon Metabolic Control, Maternal and Neonatal Outcomes. International Journal of Caring Sciences. 2014; 7(1): 313-323.

[40] Ehrlich SF, Sternfeld B, Krefman AE, et al. Moderate and vigorous intensity exercise during pregnancy and gestational weight gain in women with gestational diabetes. Maternal and Child Health Journal. 2016; 20(6): 1247-1257. PMid: 26955997. https://doi.org/10 $.1007 / \mathrm{s} 10995-016-1926-z$

[41] Alia A, Ahmad R, Husain M. Feto-Maternal Complications in Gestational Diabetes and in Pre-Existing Diabetes Mellitus. In Med. Forum. 2020; 31(4):45.

[42] Ouyang K, Mu SP, Li Y, et al. Study of the impact of control the blood sugar on neonatal outcomes with gestational diabetes mellitus. Journal of Guizhou Medical University. 2016; 41: 931-934.

[43] Elshair AA. Gestational diabetes in united nation relief and working agency health clinics in gaza strip: impact of educational program. $\mathrm{Cu}$ theses. 2020.

[44] Zhou W, Yu J, Wu Y, et al. Hypoglycemia incidence and risk factors assessment in hospitalized neonates. The Journal of MaternalFetal \& Neonatal Medicine. 2015; 28(4): 422-425. PMid: 25308104. https://doi.org/10.3109/14767058.2014.918599 